\title{
Obtenção de plantas de feijão-caupi resistentes ao Cowpea severe mosaic virus e ao Cowpea aphid-borne mosaic virus
}

\author{
Gislanne Brito Barros ${ }^{1}$; Maria do Socorro da Rocha Nogueira²; Cláudia Roberta Ribeiro de Oliveira' ${ }^{1}$; Francisco \\ Rodrigues Freire Filho²; Valdenir Queiroz Ribeiro²; Carlos Frederico de Menezes Veiga ${ }^{3}$; Paulo Sérgio Torres \\ Brioso ; Marcelo Eiras ${ }^{5}$
}

\begin{abstract}
${ }^{1}$ Universidade Estadual do Norte Fluminense, Avenida Alberto Lamego, 2000 - Parque Califórnia, Campos dos Goytacazes - RJ, 28013-602; ${ }^{2}$ Embrapa Meio-Norte, Teresina, PI; ${ }^{3}$ Universidade Federal Rural do Rio de Janeiro, Campus Leonel Miranda, Campos de Goytacazes, RJ; ${ }^{4}$ Universidade Federal Rural do Rio de Janeiro, Rod BR 465, Km 7 Seropédica-RJ; ${ }^{5}$ Instituto Biológico, São Paulo-SP.
\end{abstract}

Autor para correspondência: Gislanne Brito Barros (gislannebio@yahoo.com.br)

Data de chegada: 05/07/2012. Aceito para publicação em: 13/04/2013.

\section{RESUMO}

Barros, G.B.; Nogueira, M.S.R.; Oliveira, C.R.R.; Freire Filho, F.R.;Ribeiro, V.Q.; Veiga, C.F.M.; Brioso, P.S.T.; Eiras, M. Obtenção de plantas de feijão-caupi resistentes ao Cowpea severe mosaic virus e ao Cowpea aphid-borne mosaic virus. Summa Phytopathologica, v.39, n.2, p.130136, 2013.

Dentre os vírus que infectam o feijão-caupi (Vigna unguiculata L. Walp.) destacam-se, respectivamente, pela severidade e ampla ocorrência o Cowpea severe mosaic virus (CPSMV) e o Cowpea aphidborne mosaic virus (CABMV). Portanto, objetivaram-se, no presente trabalho, obter e avaliar plantas de feijão-caupi com resistência ao CPSMV e ao CABMV, visando ao desenvolvimento de cultivares essencialmente derivadas e novas cultivares. Realizaram-se oito cruzamentos seguidos de retrocruzamentos, utilizando a linhagem TE 97-309G-9 e a cultivar Patativa como genitores resistentes, e as cultivares BR3-Tracuateua, BRS-Urubuquara, BRS-Novaera, BRSGuariba e Pretinho como genitores suscetíveis. As gerações $F_{2}$ e $F_{2} R C_{1}$ foram desafiadas quanto à resistência por meio de inoculação mecânica com isolados do CPSMV e do CABMV. Nas gerações $\mathrm{F}_{2} \mathrm{RC}_{1}$, além da resistência foram avaliados os caracteres: número de dias para o início da floração, comprimento das vagens, número de grãos. vagem ${ }^{-1}$, peso de cem grãos e produção de grãos.planta ${ }^{-1}$. Todos os indivíduos $\mathrm{F}_{2}$ e $\mathrm{F}_{2} \mathrm{RC}_{1}$ foram analisados pelo teste $\chi^{2}$ e se ajustaram à frequência esperada de 15 plantas suscetíveis 1 planta resistente a ambos os vírus. As médias das plantas $\mathrm{F}_{2} \mathrm{RC}_{1}$ resistentes, de cada retrocruzamento, foram comparadas com a média do seu respectivo genitor recorrente pelo teste ' $\mathrm{t}$ ' e as médias dos retrocruzamentos foram comparadas pelo teste de Scott-Knott. Foi detectada variabilidade genética entre os retrocruzamentos para todos os caracteres. Todos os retrocruzamentos foram considerados promissores para produção de cultivares essencialmente derivadas resistentes ao CPSMV e ao CABMV e as plantas selecionadas possuem características que possibilitam a seleção de linhagens com grãos de bom padrão comercial e altamente produtivas.

Palavras-chave adicionais: Vigna unguiculata, Comovirus, Potyvirus, melhoramento genético.

\section{ABSTRACT}

Barros, G.B.; Nogueira, M.S.R.; Oliveira, C.R.R.; Freire Filho, F.R.;Ribeiro, V.Q.; Veiga, C.F.M.; Brioso, P.S.T.; Eiras, M. Obtaining cowpea plants resistant to Cowpea severe mosaic virus and Cowpea aphid-borne mosaic virus. Summa Phytopathologica, v.39, n.2, p.130-136, 2013.

Among the viruses that infect cowpea (Vigna unguiculata L. Walp.), Cowpea severe mosaic virus (CPSMV) and Cowpea aphidborne mosaic virus (CABMV) are highlighted for their severity and widespread occurrence, respectively. Therefore, the aim of this study was to obtain and evaluate cowpea plants showing resistance to CPSMV and CABMV in order to develop new and essentially derived cultivars. Eight crosses were performed, followed by backcrosses, using the line TE 97-309G-9 and the cultivar Patativa as resistant parental donors, and the cultivars BR3-Tracuateua, BRS-Urubuquara, BRS-Novaera, BRS-Guariba and Pretinho as susceptible parents. Generations F2 and F2RC1 were challenged for resistance by mechanically inoculating CPSMV and CABMV isolates. In F2RC1 generations, besides resistance, other traits were evaluated: number of days to the beginning of flowering, pod length, number of seeds.pod-1, weight of 100 seeds, and yield of seeds.plant-1. All F2 and F2RC1 individuals were analyzed by the $\chi^{2}$ test and fit to the expected frequency of 15 susceptible plants: 1 plant resistant to both viruses. The means of resistant F2RC1 plants, from each backcross, were compared with the mean of their respective recurrent parent by the t-test and means of backcrosses were compared by the Scott-Knott test. Genetic variability among backcrosses was detected for all traits. All backcrosses were considered promising for obtaining essentially derived cultivars resistant to CPSMV and CABMV, and the selected plants have characteristics that allow the selection of lines with highly productive grains of good commercial quality.

Additional keywords: Vigna unguiculata, Comovirus, Potyvirus, genetic breeding. 
O feijão-caupi (Vigna unguiculata (L.) Walp.) é uma importante fonte de proteína dos países tropicais e subtropicais. As doenças, sobretudo aquelas causadas por vírus, estão entre os principais fatores que contribuem para os baixos rendimentos da cultura causando grandes prejuízos (11). Dentre os principais vírus que infectam a cultura do caupi, merecem destaque, pela severidade e pela ampla ocorrência, respectivamente, o Cowpea severe mosaic virus (CPSMV) e o Cowpea aphid-borne mosaic virus (CABMV). O CPSMV, gênero Comovirus, família Secoviridae, não é transmitido por sementes (10) e em condições naturais é disseminado por mais de dez espécies de coleópteros (11). O "mosaico severo do caupi”, induzido pelo CPSMV, pode reduzir a produção de feijão-caupi em até $85 \%$, dependendo da época de inoculação e da suscetibilidade da cultivar (4). O controle efetivo dessa virose se dá por meio da utilização de variedades resistentes, sendo que fontes de resistência ao CPSMV em feijãocaupi têm sido relatadas por Lima et al. (8); Lima et al. (9) Paz et al. (20); Rocha et al. (22); Nogueira (16); Camarço et al. (5); Oliveira et al. (18). Por outro lado o CABMV gênero Potyvirus, família Potyviridae, pode ser transmitido por meio de sementes infectadas (23) e na natureza de forma não-persistente por afídeos, destacando-se Aphis craccivora Koch como o principal vetor (11). Apesar de o CABMV isoladamente provocar menores perdas na produção, a infecção simultânea com o CPSMV pode ocasionar sintomas mais severos, devido ao sinergismo entre esses vírus, ocasionando maiores perdas (27). Assim como mencionado para o CPSMV, a maneira mais eficiente para o controle do CABMV é a utilização de variedades resistentes $(3,9,11,18,22$, 26). O estudo da base genética da resistência ao CPSMV e ao CABMV tem apontado, na maioria das vezes, para uma herança recessiva monogênica $(1,2,26)$.

Este trabalho teve como objetivo obter e avaliar plantas de feijãocaupi com resistência ao CPSMV e CABMV, por meio de retrocruzamento, visando ao desenvolvimento de cultivares essencialmente derivadas e de novas cultivares.

\section{MATERIAL E MÉTODOS}

Para a obtenção das populações segregantes foram realizados cruzamentos e retrocruzamentos, utilizando como genitores doadores dos genes de resistência a linhagem TE97-309G-9, desenvolvida pela Embrapa Meio-Norte, e a cultivar Patativa procedente do estado do Ceará, ambas resistentes ao CPSMV e CABMV. Como genitores recorrentes foram utilizadas as cultivares comerciais BR3 Tracuateua, BRS Urubuquara, BRS Guariba, BRS Novaera, desenvolvidas pela
Embrapa Meio-Norte, e a cultivar local Pretinho, oriunda do estado do Pará, escolhidas por possuírem alta capacidade de rendimento, uma grande aceitação comercial e por terem como fator limitante a suscetibilidade a ambos os vírus (Tabela 1).

Os isolados de CPSMV e de CABMV foram obtidos a partir de plantas de feijão-caupi, naturalmente infectadas, coletadas no campo experimental da Embrapa Meio-Norte, em Teresina, PI. Para a purificação biológica dos vírus foram realizadas sucessivas inoculações nas linhagens TE 97-200-49F, TE 94-256-2E, diferenciadoras do CPSMV sorotipos I e II, respectivamente e na cultivar Pampo, diferenciadora do CABMV. Em seguida, os isolados purificados foram mantidos em plantas em gaiolas com tela antiafídeos. A pureza dos isolados virais foi avaliada e confirmada por meio de PTA-ELISA (Plate Traped Antigen - Enzyme Linked Immunosorbent Assay) (7) com antissoro policlonal específico contra o CABMV. As leituras de absorbância $\left(\mathrm{A}_{405} \mathrm{~nm}\right)$ foram feitas após a aplicação do substrato (pnitrofenilfosfato) utilizando-se o aparelho Microplate reader 3550$U V$ (Bio-Rad), sendo os resultados analisados pela relação da média das leituras (em triplicata) das amostras infectadas sobre a leitura (em triplicata) das amostras sadias (I/S). Além disso, foi extraído RNA das folhas de feijão-caupi infectados (6), sendo a RT-PCR realizada a partir de cerca de $1 \mu \mathrm{g}$ de RNA total, em presença de oligonucleotídeos específicos desenhados para a amplificação de porções genômicas do CABMV e do CPSMV. Foram utilizados para o CPSMV oliogonucleotídeos antisense (5'CTCAAACCCCTGTTGGGACCACA - 3') e sense (5'GGATGAATTTTTGATGGCATGG - 3') e para o CABMV os oligonucleotídeos antisense (5'-GTGCTACTGCTTCTCTGG - 3') e sense (5'-TCGACTTTGACTATGACG - 3') (16). As reações foram realizadas em termociclador (PTC100, MJ Research) e os fragmentos de DNA amplificados visualizados em gel de agarose $1,2 \%$, corado com brometo de etídeo, sob luz ultravioleta.

Sete cruzamentos biparentais e um cruzamento triplo foram realizados para obtenção de sementes $F_{1}$, que por autofecundação produziram sementes $F_{2}$ (Tabela 2). Os genitores, juntamente com sementes $\mathrm{F}_{2}$, foram semeados em copos plásticos com capacidade de $250 \mathrm{~mL}$ contendo solo esterilizado. Para cada genitor e cruzamento utilizaram-se 10 e 180 copos, respectivamente, cultivando-se duas plantas por copo.

Seis dias após o plantio foi realizada a primeira inoculação nas plantas $\mathrm{F}_{2}$ e nos genitores, utilizando-se uma mistura de tecido foliar infectado com os isolados do CPSMV sorotipo I e II e CABMV, numa proporção de 0,33g (CPSMV I), 0,33g (CPSMV II) e 0,33g (CABMV) para $9 \mathrm{~mL}$ de tampão fosfato de sódio $0,1 \mathrm{M}$ e pH 7,5, procedendo-se

Tabela 1. Características dos genitores selecionados para os cruzamentos visando resistência do feijão caupi ao Cowpea severe mosaic virus (CPSMV) e Cowpea aphid-borne mosaic virus (CABMV).

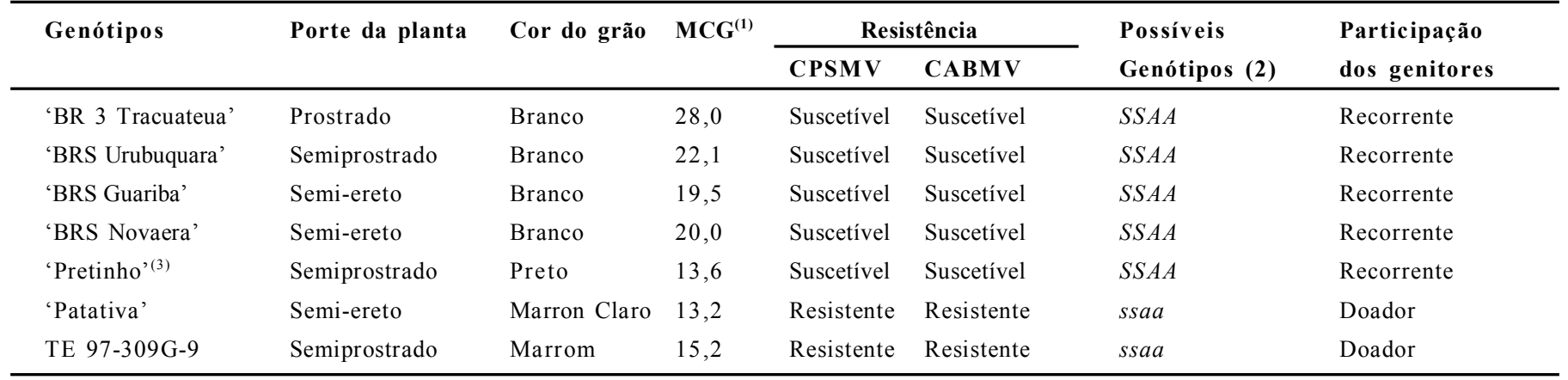

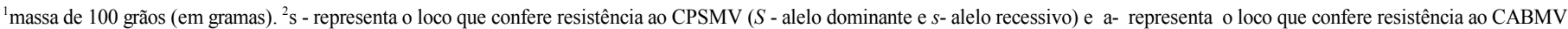
( $A$ - alelo dominante e $a$ - alelo recessivo). ${ }^{3}$ Cultivar local da região Bragantina do Estado do Pará. 
Tabela 2. Cruzamentos de feijão caupim com seus respectivos códigos.

\begin{tabular}{ll}
\hline Código dos cruzamentos & Genitores dos cruzamentos \\
\hline 1. MNC 07-910 & BR3 Tracuateua x TE 97-309G-9 \\
2. MNC 07-912 & BRS Urubuquara x TE 97-309G-9 \\
3. MNC 07-914 & BRS Novaera x TE 97-309G-9 \\
4. MNC 07-915 & Pretinho x TE 97-309G-9 \\
5. MMC 07-919 & BR3 Tracuateua x Patativa \\
6. MNC 07-921 & BRS Urubuquara x Patativa \\
7. MNC 07-922 & BRS Novaera x Patativa \\
8. MNC 07-923 & Guariba x (Pretinho x TE 97-309G-9) \\
\hline
\end{tabular}

a maceração do tecido foliar infectado, acrescido de celite (Sigma) 0,1 $\mathrm{g}$ de folha-1 (16). Uma semana depois, efetuou-se a re-inoculação com objetivo de assegurar a infecção dos genótipos suscetíveis. As plantas foram inspecionadas durante 30 dias, e as que apresentavam sintomas de mosaico, bolhas, deformação foliar e/ou lesão necrótica foram descartadas. As plantas consideradas resistentes foram transplantadas e mantidas em telado. Aquelas que apresentaram sintomas após o transplantio também foram eliminadas. As plantas assintomáticas foram utilizadas para a realização de retrocruzamentos com seu respectivo genitor recorrente. Foram obtidas as sementes $\mathrm{F}_{1} \mathrm{RC}_{1}$ e por autofecundação, as $\mathrm{F}_{2} \mathrm{RC}_{1}$ de cada retrocruzamento, que juntamente com os respectivos genitores foram semeadas em bandejas, contendo solo esterilizado. Seis dias após a germinação foi realizada a inoculação, em ambos, utilizando-se a mesma mistura de isolados e a mesma metodologia adotada em $\mathrm{F}_{2}$. Para estimar o número mínimo de plantas a serem inoculadas nas gerações $\mathrm{F}_{2}$ e na $\mathrm{F}_{2} \mathrm{RC}_{1}$ que assegurasse a presença, com 0,90 de probabilidade dos genótipos com resistência ao CPSMV e CABMV, utilizou-se a fórmula $\mathrm{n}=\log (1-\mathrm{P}) / \log (1-\mathrm{p})$, em que $\mathrm{n}$ refere-se ao número mínimo de plantas que devem ser inoculadas para obter-se pelo menos uma planta resistente, $\mathrm{P}$, a probabilidade desejada e p, a probabilidade de ocorrência do genótipo $(21,25)$. Determinou-se, portanto, a necessidade de se inocular, no mínimo, 36 plantas para que se obtivesse pelo menos uma planta com resistência aos dois vírus. Na geração $\mathrm{F}_{2}$ foram inoculadas 300 plantas e na geração $\mathrm{F}_{2} \mathrm{RC}_{1}$, em média, 512 plantas foram inoculadas, dependendo da disponibilidade de sementes.

Plantas da geração $\mathrm{F}_{2} \mathrm{RC}_{1}$ que não apresentaram sintomas dos vírus foram transplantadas para telado para a caracterização morfoagronômica e aquelas que apresentaram sintomas após serem transplantadas foram eliminadas. Nessas populações, além da resistência, os seguintes caracteres foram avaliados: número de dias para o início da floração (NDIF), comprimento de vagem (CPV), número de grãos por vagem (NGV), massa de cem grãos (MCG) e produtividade de grãos por planta (PGP).

As frequências das segregações observadas foram avaliadas em relação às frequências esperadas pelo teste $\chi^{2}$ (Qui-Quadrado), tanto na geração $F_{2}$ dos cruzamentos biparentais e do cruzamento triplo quanto na $F_{2} R_{1}$. Em seguida, realizou-se também o teste de heterogeneidade (13).

A análise estatística dos dados fenológicos coletados nas $\mathrm{F}_{2} \mathrm{RC}_{1}$ foi precedida por uma análise de resíduo. Para os caracteres NDIF e NGV efetuou-se uma transformação dos dados para $\sqrt{x}$. O delineamento adotado foi o inteiramente casualizado, com número de repetições desiguais. As análises estatísticas foram realizadas utilizando-se o programa estatístico SAS (24), e as médias foram ajustadas pelo método da soma mínima dos quadrados empregando-se o procedimento LSMEANS do SAS.
Foi utilizado o teste " $t$ " de Student para a comparação das médias das plantas $\mathrm{F}_{2} \mathrm{RC}_{1}$ resistentes com seu respectivo parental recorrente e o teste de Scott-Knott, ao nível de 0,05 de probabilidade, para o agrupamento das médias (28).

\section{RESULTADOS E DISCUSSÃO}

A segregação da geração $\mathrm{F}_{2}$ está de acordo com a proporção esperada de 15 suscetíveis: 1 resistente. $O$ teste de heterogeneidade dessa geração, envolvendo os oito cruzamentos, mostrou que houve homogeneidade na segregação, na proporção de 15 suscetíveis: 1 resistente. Contudo, na segregação das gerações $\mathrm{F}_{2} \mathrm{RC}_{1}$, o teste de heterogeneidade incluindo os oito cruzamentos, mostrou que não houve homogeneidade. Esse resultado pode ser justificado pelos valores de $\chi^{2}$ muito acima do esperado nos retrocruzamentos $\{[$ ('BR3-Tracuateua' x 'Patativa') x 'BR3-Tracuateua']\} e \{['BRS-Guariba' x ('Pretinho' $x$ TE 97-309G-9)] x 'BRS-Guariba'\} (Tabela 3). As evidências indicam que os desvios, nessas populações, ocorreram devido a uma infecção fúngica, possivelmente causada por Colletotrichum truncatum (Schw.) Andrus \& Moore, após o transplantio para o solo. As plantas foram eliminadas com o surgimento dos primeiros sintomas do fungo para evitar que o mesmo se disseminasse dentro do telado. Entretanto, fazendo-se o teste de heterogeneidade excluindo-se essas duas populações, as segregações mostraram-se homogêneas, na proporção de 15 suscetíveis: 1 resistente. Estes resultados estão de acordo com estudos prévios sobre a herança de resistência ao CPSMV e ao CABMV, os quais têm revelado a existência de genes recessivos monogênicos $(1,2,26)$.

Houve a confirmação do CPSMV a partir de RT-PCR resultando na amplificação de fragmentos de DNA com tamanho esperado de 592 pares de bases (dados não mostrados). A presença do CABMV por meio de PTA-ELISA com antissoro policlonal específico, foram consideradas positivas nas análises em que se obtiveram valores (médias-triplicata) três vezes superiores às amostras sadias (dados não mostrados).

Para todos os caracteres estudados, os valores do quadrado médio diferiram significativamente pelo teste $t(p<0,01)$, evidenciando a existência de alta variabilidade genética para estas características. Estes resultados corroboram aqueles obtidos por Lopes et al. (12) que também constataram valores significativos para esses caracteres avaliando linhagens de feijão-caupi. Para os caracteres NDIF, CPV, NGV, PCG, a magnitude do CV foi inferior a $10 \%$, indicando boa precisão experimental na condução dos trabalhos (Tabela 4).

A comparação de média da geração $\mathrm{F}_{2} \mathrm{RC}_{1}$ com a média do genitor recorrente, feita pelo teste $t$ mostrou diferença significativa ao nível de 0,01 de probabilidade para todos os caracteres na maioria dos retrocruzamentos. Apenas no retrocruzamento [('BRS Novaera' $x$ 'Patativa') x 'BRS Novaera'], o caráter número de grãos por vagens foi significativo a 0,05 de probabilidade. Nos retrocruzamentos [('Pretinho' x 'TE 97-309G-9') x 'Pretinho'] e [('BR3 Tracuateua' x 'Patativa') $\mathrm{x}$ 'BR3 Tracuateua'] não houve diferença significativa para o caráter comprimento de vagem. Para o caráter número de dias para o início da floração, as médias das plantas resistentes de todos os retrocruzamentos foram superiores ao seu respectivo genitor recorrente. No caráter comprimento de vagem, cinco retrocruzamentos apresentaram as médias das plantas resistentes superiores à média do respectivo genitor recorrente. Vale ressaltar que vagens grandes estão diretamente relacionadas com produtividade, uma vez que, quanto maior a vagem, maior é o número de grãos por vagem, facilitando ainda 


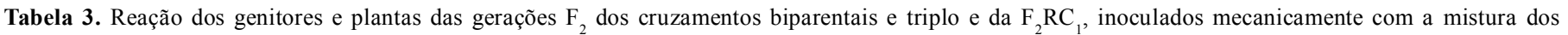
vírus Cowpea severe mosaic virus e Cowpea aphid-borne mosaic virus e teste de heterogeneidade.

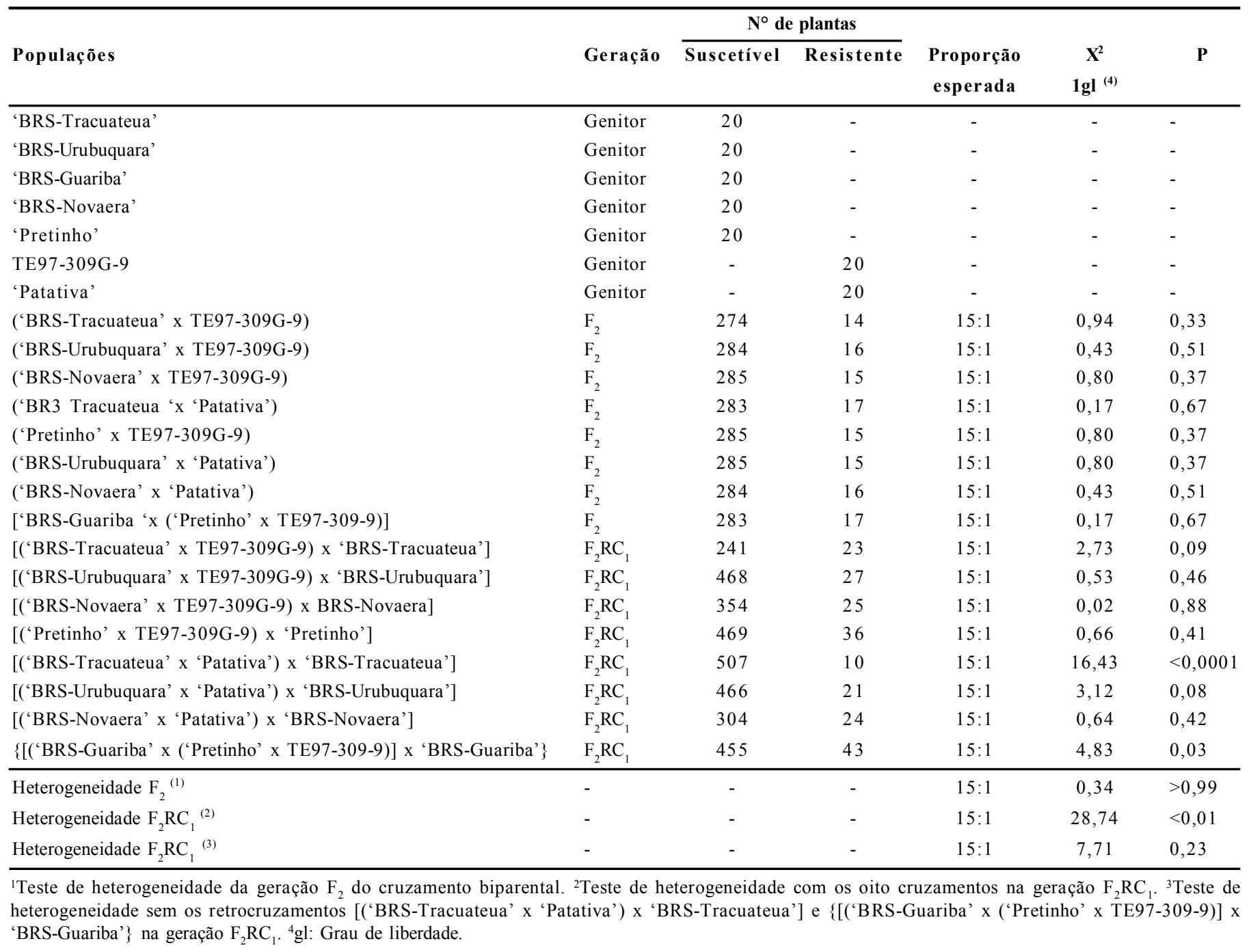

Tabela 4. Comparação de médias de cruzamentos de feijão-caupi visando à obtenção de cultivares essencialmente derivadas e novas cultivares resistentes ao Cowpea severe mosaic virus e Cowpea aphid-borne mosaic virus, pelo teste Scott e Knott ao nível de 0,05 de probabilidade.

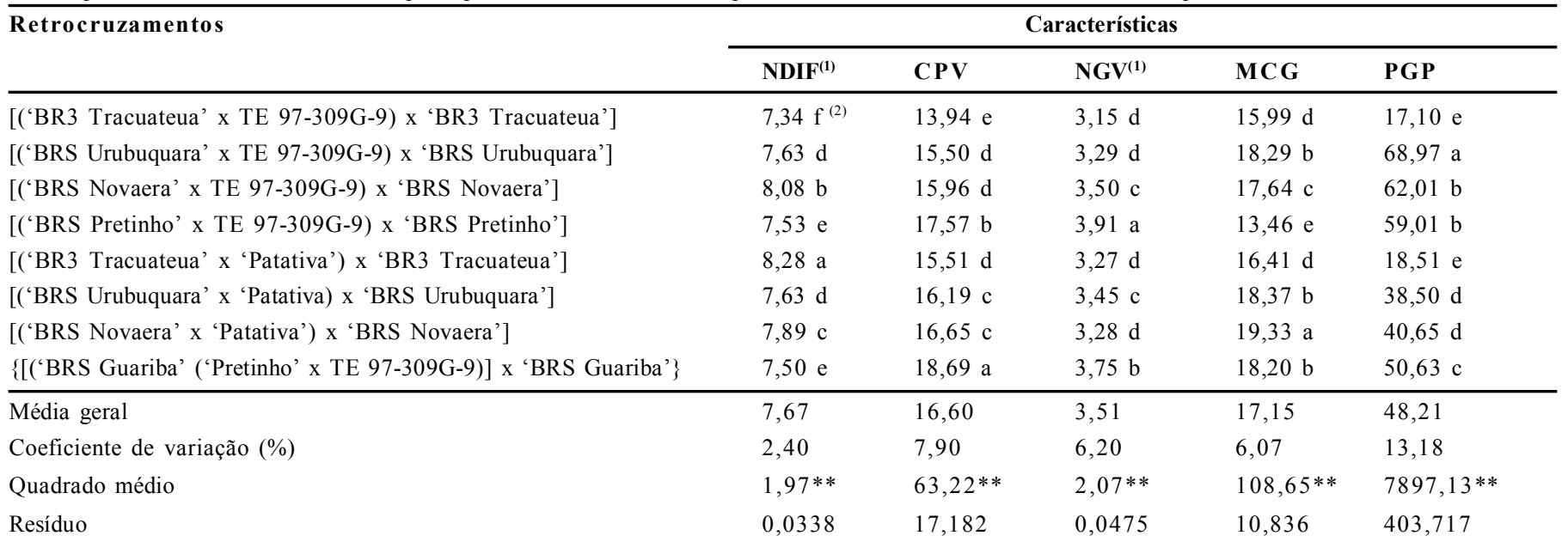

Número de dias para o início da floração (NDIF); Comprimento de vagem (CPV); Número de grãos por vagem (NGV), massa de cem grãos (MCG) e Produtividade de grãos da planta (PGP).

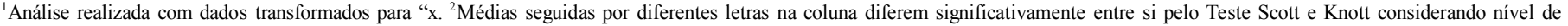
0,05 de probabilidade. ${ }^{* *}$ Significativo pelo teste $t$ considerando nível de 0,05 de probabilidade. 
Tabela 5. Comparação de médias das plantas de feijão-caupi, $\mathrm{F}_{2} \mathrm{RC}_{1}$ resistentes com seus respectivos genitores recorrentes pelo teste $t$.

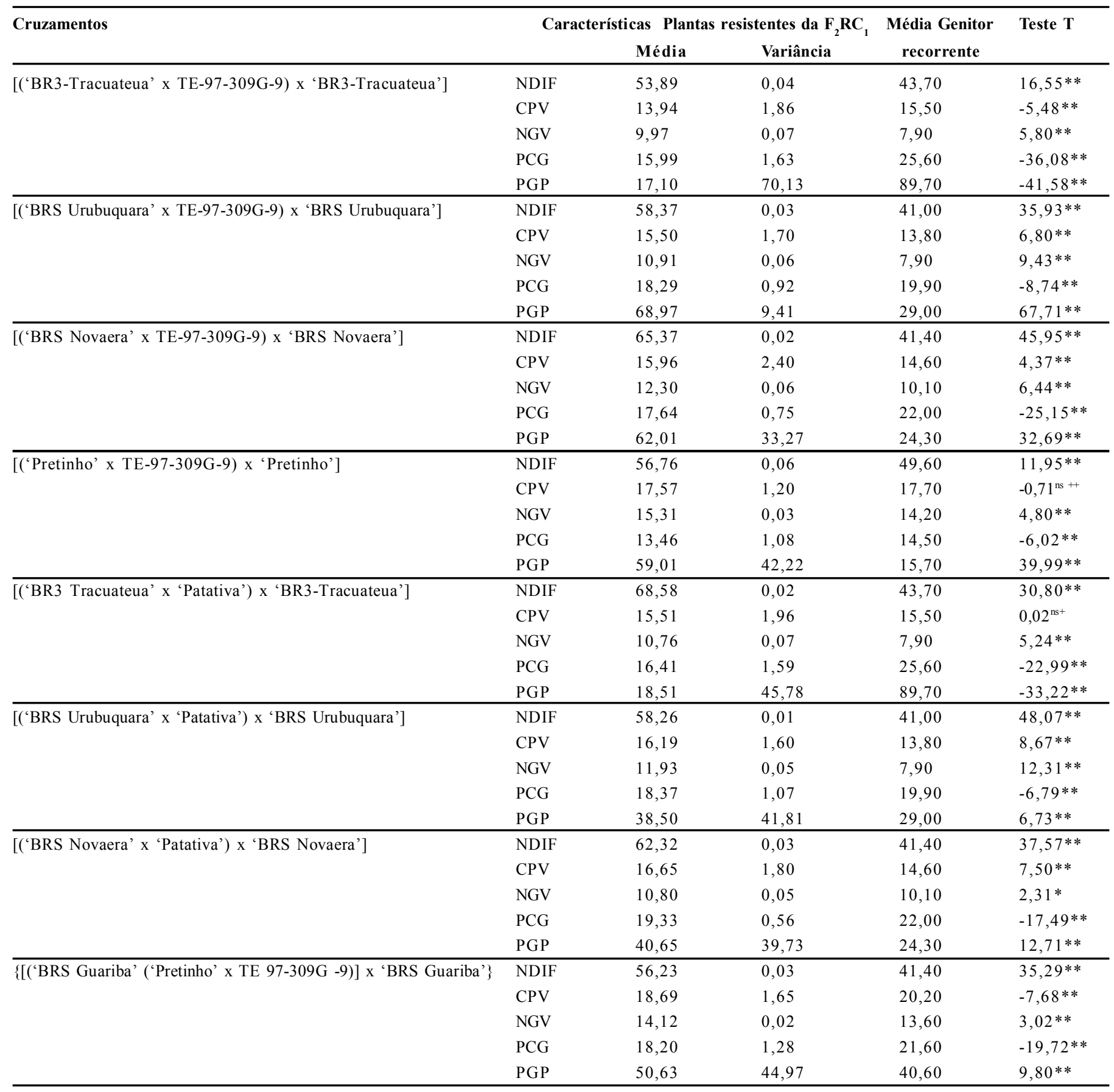

Número de dias para o início da floração (NDIF); Comprimento de vagem (CPV); Número de grãos por vagem (NGV), Massa de cem grãos (MCG) e Produtividade de grãos da planta (PGP)."

** Significativo pelo teste $t$ ao nível de 0,05 e 0,01 de probabilidade, respectivamente. ${ }^{\text {Ns }}$ Não significativo pelo teste 't' ao nível de 0,05 e 0,01 de probabilidade. ${ }^{+,+}$significativo a 0,50 e 0,25 de probabilidade, respectivamente.

a colheita manual. No que se refere ao caráter número de grãos por vagem, as plantas resistentes de todos os retrocruzamentos superaram a média do seu respectivo genitor recorrente, com destaque para o retrocruzamento [('Pretinho' x TE-97-309G-9) x 'Pretinho'], ficando dentro da média obtida por Silva \& Neves (27). Para a massa de cem grãos, as médias dos genitores recorrentes foram superiores às médias das plantas resistentes de todas as populações $\mathrm{F}_{2} \mathrm{RC}_{1}$. Este caráter não pode ser alterado com o processo de seleção, pois geralmente os consumidores preferem vagens mais compridas por apresentarem maior rendimento e grãos maiores. Para o caráter produtividade de grãos por planta, as médias das progênies resistentes foram superiores às médias dos genitores recorrentes. Exceção feita ao genitor recorrente 'BR3 Tracuateua' que apresentou média superior à média de seus respectivos retrocruzamentos (Tabela 5).

O teste de Scott-Knott permitiu detectar diferenças para todos os caracteres, confirmando a existência de variabilidade genética entre retrocruzamentos. No caráter número de dias para o início da floração, dados transformados para $\sqrt{x}$, o retrocruzamento mais precoce foi 
o [('BR3 Tracuateua' x TE 97-309G-9) x 'BR3 Tracuateua'], o qual diferiu estatisticamente dos demais. No caráter comprimento da vagem, dois retrocruzamentos se destacaram por apresentarem médias acima de $17,1 \mathrm{~cm}$. O retrocruzamento \{[('BRS Guariba' x ('Pretinho' x TE 97-309G-9)] x 'Guariba'\} apresentou o maior comprimento de vagem, seguido do retrocruzamento [('Pretinho' x TE 97-309G-9) x 'Pretinho'], porém diferiram significativamente entre si. Oliveira et al. (17), em um estudo envolvendo linhagens e cultivares de feijão-caupi, encontraram valores médios de comprimento de vagem variando de $17,0 \mathrm{~cm}$ a 26,0 $\mathrm{cm}$. Para o caráter número de grãos por vagem, dados transformados para $\sqrt{x}$, os retrocruzamentos foram separados em quatro grupos. Nesse caráter destacou-se o retrocruzamento [('Pretinho' x TE $97-$ 309G-9) x 'Pretinho'] diferindo significativamente dos demais. Matos Filho et al. (14), avaliando o potencial produtivo em progênies de feijão-caupi, encontraram valor médio para esse caráter de 7,15 grãos.vagem ${ }^{-1}$, semelhante à média geral dos retrocruzamentos. $\mathrm{O}$ caráter massa de cem grãos apresentou média geral de 17,15 g. Nesse caráter foram formados cinco grupos, com destaque para o retrocruzamento [('BRS Novaera' $x$ 'Patativa') x 'BRS Novaera'] com massa de cem grãos de 19,33 g. A literatura permite concluir que tanto no Brasil quanto na Nigéria, terceiro maior produtor e consumidor mundiais de feijão-caupi, respectivamente, a preferência é por grãos grandes, porém nas cultivares comerciais o referido caráter predomina na faixa de $11,8 \mathrm{~g}$ a $18,7 \mathrm{~g}(15,19)$. No caráter produtividade de grãos por planta houve a formação de cinco grupos, com a média variando de $17,10 \mathrm{~g} \mathrm{a}$ $68,97 \mathrm{~g}$. A média geral foi de 48,21 g. O retrocruzamento que mais se destacou foi o [('BRS Urubuquara' x TE 97-309G-9) x 'BRS Urubuquara'], diferindo estatisticamente dos demais (Tabela 4).

Os resultados obtidos permitem concluir que: a) A segregação conjunta dos genes de resistência ao CPSMV e ao CABMV obedece à proporção de 15 suscetíveis : 1 resistente; b) Há variabilidade genética entre os retrocruzamentos para os caracteres avaliados e c) Os retrocruzamentos possuem segregantes promissores com potencial a seleção de cultivares essencialmente derivadas e para a obtenção de novas linhagens com grãos de bom padrão comercial e altamente produtivas, em ambos os casos com resistência ao CPSMV e ao CABMV.

\section{REFERÊNCIAS BIBLIOGRÁFICAS}

1. Assunção, I.P.; Melo-Filho, L.R.; Resende, L.V.; Barros, M.C.S.; Lia, G.S.A.; Coelho, R.S.B.; Lima, J.A.A. Genes diferentes podem conferir a resistência ao Cowpea severe mosaic virus em caupi. Fitopatologia Brasileira, v. 30, n. 3, p. 274-278, 2005.

2. Bashir, M.; Ahmad, Z.; Ghafoor, A. Cowpea aphid-borne mosaic potyvirus: a review. International Journal of Pest Management, London, v. 48, n.2, p. 155-168, 2002.

3. Bashir, M.; Hampton, O. Detection and identification of seed borne viruses from cowpea (Vigna unguiculata (L.) Walp.) germoplasm. Plant Pathology, Oxford, v. 45, p. 54-58, 1996.

4. Booker, H. M.; Umaharan, P.; Mcdavid, C.R. Effect of Cowpea severe mosaic virus on crop growth characteristics and yield of cowpea. Plant Disease, St Paul, v. 89, p. 515-520, 2005.

5. Camarço, R.F.E.A.; Nascimento, A.K.; Andrade, E.C.; Lima, J.A.A. Biological, serological and molecular comparison between isolates of Cowpea severe mosaic virus. Tropical Plant Pathology, Brasilia, v. 34, n. 4, p. 239-244, 2009.

6. Chomczynsk, P.; Sacchi, N. Single-step method of RNA isolation by acid guanidinium thiocyanate-phenol-chloroform extration. Analytical Biochemistry, New York, v.162, p. 156-159, 1987.

7. Converse, R.; Martin, R. Enzime- linked immunosorbent assay. In: Hampton, R.O.; Ball, E.M.; DE Boer, S.H. (Eds.) Serological methods for detection and identification of viral and bacterial plant pathogens. Saint Paul: American Phytopathological Society, 1991. p.179-204.

8. Lima, J.A.A.; Santos, C.D.G.; Silveira, L.F.S. Comportamento de genótipos de caupi em relação aos dois principais vírus que ocorrem no Ceará. Fitopatologia Brasileira, Brasília, v. 11, p. 151-161, 1986.

9. Lima, J.A.A.; Silva, A.K.F.S; Aragão, M.L.; Ferreira, N.R.A; Teófilo, E.M. Simple and multiple resistances to viruses in cowpea genotypes, Pesquisa Agropecuária Brasileira, Brasília, v. 46, n. 11, 1432-1438, 2011.

10. Lima, J.A.A.; Silveira, L.F.S.; Oliveira, J.P. Não transmissibilidade de "Cowpea Severe Mosaic Virus" por sementes de Vigna unguiculata cvs. Pitiúba e Seridó. Fitopatologia Brasileira, Brasília, v. 14 , p. $50-44,1989$.

11. Lima, J.A.A.; Sittolin, I.M.; Lima, R.C.A. Diagnoses e Estratégias de Controle de Doenças Ocasionadas por Vírus. In: Freire Fi1ho, F.R. et al. (Eds). Feijão-Caupi: avanços tecnológicos. 2005. p. 405-459.

12. Lopes, A.C.A.; Freire Filho, F.R.; Silva, R.B.Q.; Campos, F.L.; Rocha, M.R. Variabilidade e correlações entre caracteres agronômicos em caupi (Vigna unguiculata). Pesquisa Agropecuária Brasileira, Brasília, v. 36, n. 3, p. 515-520, 2001.

13. Mather, $K$. The measurement of linkage in heredity. 2. ed. London: Methuen, 1951.149p.

14. Matos Filho, C.H.A.; Gomes, R.L.F.; Rocha, M.M.; Freire Filho, F.R.; Lopes, A.C. A. Potencial produtivo de progênies de feijãocaupi com arquitetura ereta de planta. Ciência Rural, Santa Maria, v.39, n.2, p. 348-354, 2009.

15. Mishili, F.J.; Fulton, J.; Shehu, M.; Kushwaha, S.; Marfa, K.; Jamal, M.; Kergma, A.; Deboer, J.L. Consumer preferences for quality characteristics along the cowpea value Chain in Nigeria, Ghana, and Mali, Agribusiness, v.25, n.1, p.16-35, 2009.

16. Nogueira, M.S.R. Diferenciação molecular de sorotipos virais e estudo da resistência ao Cowpea severe mosaic virus e Cowpea aphid-borne mosaic virus em caupi. 2007. $141 \mathrm{f}$. Dissertação (Doutorado em Biotecnologia Vegetal) - Universidade Federal do Rio de Janeiro.

17. Oliveira, A.P.; Tavares Sobrinho, J.; Nascimento, J.T; Alves, A.U.; Albuquerque, I.C.; Bruno, G.B. Avaliação de linhagens e cultivares de feijão-caupi, em Areia, PB. Horticultura Brasileira, Brasília, v. 20 , n. 2 , p. $180-182,2002$.

18. Oliveira, C.R.R.; Freire Filho, F.R.; Nogueira, M.S.R.; Barros, G.B.; Eiras, M.; Ribeiro V.Q.; Lopes, A.C.A. Reação de genótipos de feijão-caupi revela resistência às coinfecções pelo Cucumber mosaic virus, Cowpea aphid-borne mosaic virus e Cowpea severe mosaic vírus. Bragantia, Campinas, v. 71, n. 1, p.59-66, 2012.

19. Passos, M.M.; Silva, S.A.; Cruz, P.J.; Rocha, M.M.; Cruz, E.M.O.; Rocha, M.A.C.; Bahia, H.F.; Saldanha, R.B. Divergência genética em feijão-caupi. Bragantia, Campinas, v. 66, n. 4, p. 579-586, 2007.

20. Paz, C.D.; Lima, J.A.A.; Pio-Ribeiro, G.; Assis Filho, F.M.; Andrade, G.P.; Gonçalves, M.F.B. Purificação de um isolado do vírus do mosaico severo do caupi, obtido em Pernambuco, produção de antissoros e determinação de fontes de resistência em caupi. Summa Phytopathologica, Jaboticabal, v.25, n.4, p.285-288, 1999.

21. Ramalho, M.A.P.; Santos. J.B. dos; Zimmermann, M.J.O. Genética quantitativa em plantas autógamas: aplicações ao melhoramento do feijoeiro. Goiânia: UFG, 1993. 271p.

22. Rocha, M.M.; Lima, J.A.A.; Freire Filho, F.R.; Rosal, C.J.S.; Lopes, A.C.A. Resistência de genótipos de caupi (Vigna unguiculata L. Walp.) de tegumento branco a isolados de vírus da famílias Bromovirídae, Comoviridae e Potyviridae. Científica Rural, Bagé, v.8, n. 1, p. 85-92, 2003.

23. Santos, F.M.L.; Lima, J.A.A.; Barreto, P.D. Infecções simples e múltiplas de vírus em caupi no Ceará. Fitopatologia Brasileira, Brasília, v. 24, n.4, p. 518-522, 1999.

24. SAS Institute. SAS/ STAT: User's guide: version 8.1. Cary, 2000. v.1.

25. Sedcole, J.R. Number of plants necessary to recovery a trait. Crop Science, Madison, v. 17, p. 667-668, 1977.

26. Silva, L.A.; Garcêz, R.M.; Chaves, A.L.R.; Colariccio, A.; Eiras, 
M. Transmissão experimental revela novos potenciais reservatórios do Cowpea aphid-borne mosaic virus, Summa Phytopathologica, Botucatu, v. 38, n. 2, p. 168-169, 2012.

27. Silva, J.A.L.; Neves, J.A. Produção de feijão-caupi semi-prostrado em cultivos de sequeiro e irrigado, Revista Brasileira Ciência Agrária, Recife, v.6, n.1, p.29-36, 2011.

28. Vale, C.C.; Lima, J. A. A. Efeitos de infecção isolada e mista de vírus de grupos distintos em caupi. Fitopatologia Brasileira, Brasília, v.19, n. 2, p.193-197, 1994.

29. Vale, C.C.; Lima, J.A.A. Herança da imunidade da cultivar Macaibo de Vigna unguiculata ao vírus do mosaico severo do caupi. Fitopatologia Brasileira, Brasília, v.20, n.1, p.30-32, 1995.

30. Zimmernann, F.J.P. Estatística aplicada à pesquisa agrícola. Santo Antônio de Goiás: Embrapa Arroz e Feijão, 2004. 402p. 